\title{
Periodontal Treatment Improves Prostate Symptoms and Lowers Serum PSA in Men with High PSA and Chronic Periodontitis
}

\section{Naif Alwithanani ${ }^{1}$, Nabil F Bissada ${ }^{1 *}$, Nishant Joshi' ${ }^{1}$, Donald Bodner ${ }^{2}$, Catherine Demko ${ }^{3}$, Gregory T MacLennan ${ }^{4}$, Robert Skillicorn ${ }^{1}$, Lee} Ponsky² and Sanjay Gupta ${ }^{2}$

${ }^{1}$ Department of Periodontics, Case Western Reserve University, Cleveland, Ohio 44106, USA

${ }^{2}$ Department of Urology, Case Western Reserve University \& University Hospitals Case Medical Center, Cleveland,

Ohio 44106, USA

${ }^{3}$ Department of Community Dentistry, Case Western Reserve University, Cleveland, Ohio 44106, USA

${ }^{4}$ Department of Pathology, Case Western Reserve University \&University Hospitals Case Medical Center, Cleveland, Ohio 44106, USA

\begin{abstract}
Objective: To assess changes in voiding symptoms, serum PSA and inflammatory cytokine levels after non-surgical periodontal treatment in men with chronic periodontitis.

Patients and methods: Twenty-seven men who underwent prostate biopsy because of abnormal findings on digital rectal examination or elevated PSA $(\geq 4 \mathrm{ng} / \mathrm{ml})$ participated in the study. Dental plaque $(\mathrm{PI})$ and gingival $(\mathrm{Gl})$ indices, bleeding on probing (BOP), probing depth (PD), clinical attachment level (CAL), gingival recession(GR), PSA, IPSS, $\mathrm{IL}-1 \beta$, and C-Reactive Protein (CRP) were determined before and after periodontal treatment. The Mann-Whitney test was used to compare PSA level at baseline with prostate inflammation, prostate malignancy, and Gleason score. The Wilcoxon Rank-Sum Test was used to examine differences in baseline and post-periodontal treatment values. Change in PSA level after periodontal treatment was correlated with change in other parameters studied, using Spearman's correlation.
\end{abstract}

Results: All clinical periodontal parameters and IPSS values showed statistically significant $(P<0.05)$ improvement after periodontal treatment. A reduction in mean PSA levels was noted 4 to 8 weeks after treatment, but did not reach statistical significance $(4.53 \pm 8.16$ versus $4.19 \pm 7.71, P=0.13)$. Men having $>4 \mathrm{ng} / \mathrm{ml} \mathrm{PSA}$ levels at baseline, showed significant $(P<0.05)$ reduction in PSA after treatment $(9.7 \pm 11.9$ versus $8.51 \pm 11.6)$. No significant change in CRP and IL-1ßlevels $(p>0.05)$ were found. Statistically significant correlation was found between the changes in periodontal parameters and PSA levels after periodontal treatment: CAL $(r=0.57, P=0.002), B O P(r=0.42, P=0.031), G I(r=0.39$, $P=0.04)$, $G R(r=0.67, P=0.001)$. Mean $P S A$ levels were significantly higher $(P=0.02)$ in men with moderate/severe prostate inflammation than in those with none/mild group $(6.5 \pm 3.6$ versus $4.3 \pm 9.1 \mathrm{ng} / \mathrm{ml})$ regardless of the presence or severity of prostate malignancy.

Conclusion: Periodontal treatment improved prostate symptom score and lowered PSA value in men afflicted with chronic periodontitis.

Keywords: Chronic prostatitis; Periodontitis; Prostate specific antigen; IPSS

\section{Introduction}

Intra-prostatic inflammation, referred as 'prostatitis' is commonly observed in the prostate biopsies or prostatectomy and benign prostatic hyperplasia specimens [1-4]. Men with chronic prostatitis often experience perineal or pelvic pain with or without irritative voiding symptoms [5-7]. Prostatitis is also a well-established cause of elevated PSA [8-10]. According to National Institutes of Health, prostatitis has been classified into four clinical categories: Category I, acute bacterial prostatitis; Category II, chronic bacterial prostatitis; Category III, chronic pelvic pain syndrome either inflammatory (IIIa) or noninflammatory (IIIb); and Category IV, asymptomatic inflammatory prostatitis $[5,11]$. Previous study from our group has demonstrated that men having both prostatitis and moderate to severe periodontitis have higher PSA levels compared to those having either condition alone [12]. Gram-negative bacteria have been suggested as etiologic agents for periodontitis and category I and II prostatitis [12,13]. A bacterial etiology for categories III and IV prostatitis, however, has not yet been identified [14]. Cytokine imbalance and altered levels of pro- and antiinflammatory cytokines has been implicated in the pathogenesis of both chronic periodontitis and prostatitis $[15,16]$. Given the similarity in etiopathogenesis of prostatitis and periodontitis, it is possible that an association between the two conditions exists, that may manifest elevated PSA levels in the circulating blood. The purpose of this study was to assess whether non-surgical periodontal treatment has an effect on prostate symptom score and serum PSA and levels of proinflammatory cytokines, viz., IL-1 $\beta$ and CRP in men with elevated serum PSA and chronic periodontitis.

\section{Materials and Methods}

\section{Study design}

This study was a collaborative effort between the Department of Periodontics at the Case Western Reserve University, School of Dental Medicine, and the Departments of Urology and Pathology at the University Hospitals Case Medical Center, Cleveland, Ohio. The protocol for the study was approved by the University Hospitals

*Corresponding author: Nabil F Bissada, DDS, MSD, Case Western Reserve University, School of Dental Medicine, 10900 Euclid Avenue, Cleveland, $\mathrm{OH}$ 44106, Tel: 216-368-6757; Fax: 216-368-3204; E-mail: nabil.bissada@case.edu

Received January 21, 2015; Accepted February 03, 2015; Published February 09, 2015

Citation: Alwithanani N, Bissada NF, Joshi N, Bodner D, Demko C, et al. (2015) Periodontal Treatment Improves Prostate Symptoms and Lowers Serum PSA in Men with High PSA and Chronic Periodontitis. Dentistry 5: 284. doi:10.4172/2161. 1122.1000284

Copyright: (c) 2015 Alwithanani N, et al. This is an open-access article distributed under the terms of the Creative Commons Attribution License, which permits unrestricted use, distribution, and reproduction in any medium, provided the original author and source are credited. 
Institutional Review Board (\#07-11-10). The transrectal ultrasound database was used to screen men who underwent prostate needle biopsy between January 2012 and August 2012. The database identified 304 men meeting initial eligibility criteria and gathered information such as: age, ethnicity, date of biopsy, reason for prostate needle biopsy, serum PSA levels, and biopsy report. These men were subsequently screened by telephone using an institutional review board-approved screening protocol to determine their eligibility and interest in the study. The following inclusion criteria was used to enroll men in the study: men $\geq 21$ years of age with confirmed inflammation of the prostate gland based on needle prostate biopsy report within the last twelve months; possessing elevated serum PSA levels ( $>4 \mathrm{ng} / \mathrm{ml}$ ) and/or other clinical presentations indicating an abnormal prostate on digital rectal examination. Other inclusion criteria include minimum of 18 teeth present and at least six teeth with: Gingival Index (GI) $\geq 1 \mathrm{~mm}$, Plaque Index $(\mathrm{PI}) \geq 1 \mathrm{~mm}$, Probe Depth (PD) $\geq 4 \mathrm{~mm}$, Bleeding on Probing (BOP), and Clinical Attachment Loss (CAL) $\geq 4-5 \mathrm{~mm}$ (mesial and distal average of a tooth i.e. $(M L+M B+D L+D B) / 4$. Men refrained from including in the study were based on the criteria including a recent ( $\leq 6$ months) myocardial infarction; stroke; organ transplant; unwillingness to undergo periodontal examination and periodontal treatment within the last month: and no antibiotic exposure within the last three months. A total of twenty-seven men participated in the study and the periodontal examination was performed by a trained periodontal examiner (NA).

Description of the periodontal condition of populations is generally based on full or partial mouth assessments of probing depths, clinical attachment loss, and gingival recession. The most widely accepted system to characterize gingival inflammation in observational and experimental studies includes the gingival index (GI) and bleeding on probing (BOP). The plaque index (PI) assesses the amount of bacterial plaque present at the gingival area of the teeth and it is scored from 0 (no plaque) to 3 (heavy accumulation of soft matter). Periodontal assessment included: PD and CAL at six sites per tooth, GI of Loe and Silness [17], PI of Loe [18], gingival recession, and percentage of sites with BOP.

The International Prostate Symptom Score (IPSS) is based on the answers to seven questions concerning urinary symptoms and one question concerning quality of life. The total score, therefore, ranges from 0 to 35 (asymptomatic to symptomatic) [19]. PSA levels, IPSS, IL$1 \beta$ and CRP levels were also determined before and after periodontal treatment. A pathologist (GTM) classified the prostate needle biopsy slides of the participants based on previously described criteria used to classify prostate inflammation [8]. Subjects were divided into two groups: $\leq 10 \%$ of chronic inflammatory cell infiltrate indicating none/ mild prostatic inflammation (group A) and $>10 \%$ for moderate/severe inflammation (group B). In the needle biopsy, the presence or absence of malignancy was coded as 1 or 2, respectively. The results were coded in a double blinded manner, so that the pathologist was not aware of the periodontal findings and vice versa.

\section{Statistical analyses}

Standard descriptive statistics was used to summarize baseline variables. Paired testing (Wilcoxon Rank Sum test) was used to compare baseline and post-periodontal treatment values; independent testing (Mann Whitney test) was used when comparing the change scores in PSA by baseline characteristics of inflammation, malignancy and baseline PSA group (normal versus elevated PSA). The relationship between the change in PSA levels with the change in clinical periodontal parameters, IPSS and IL- $1 \beta$ was examined using Spearman's rho correlation coefficients. A p value of $<0.05$ was considered as statistically significant. All statistical analyses were carried out using SPSS v20, Chicago, IL.

\section{Results}

Baseline characteristics of twenty-seven men are shown in Table 1. One person's histopathological slide was not scored for inflammation or malignant changes. Twenty-one out of 27 patients had none or mild prostate inflammation. Fifteen subjects had a biopsy-confirmed prostate malignancy with six having a Gleason score greater than 7 . Two patients had both severe prostate inflammation and malignancy (Table 2). The mean PSA level was $4.5 \mathrm{ng} / \mathrm{ml}( \pm 8.2) ; 10$ patients had a PSA value exceeding $4.0 \mathrm{ng} / \mathrm{ml}$. Serum IL- $1 \beta$ levels were low in all the participants; and 18 of 27 patients had undetectable levels of serum CRP. Thus, CRP and IL- $1 \beta$ were not included in further analysis. The average IPSS (10.6 on a scale of 0 -35) reflected self-reported symptoms that generally occurred less than half the time. At baseline, PSA levels were significantly higher in subjects with moderate to severe prostate inflammation as compared to those with none or mild $(\mathrm{P}=0.023)$. PSA levels were higher in the presence of malignancy and/or with Gleason score greater than 7 . However, these differences were not statistically significant $(\mathrm{P}=0.65$ and 0.61 , respectively). Moderate correlation was observed between PSA levels and IPSS (Spearman rho $=0.401, \mathrm{P}=0.038$, data not shown).

Clinical periodontal measures were recorded at baseline and 4 to 8 weeks after periodontal treatment. None of the 27 patients received any treatment for a prostate condition e.g. oncologic treatment, during this time period. At baseline, all study participants had moderate to severe periodontal disease. The clinical periodontal parameters showed significant improvement 4 to 8 weeks after periodontal treatment, confirming the benefit of treatment (Table 3).

The mean change in PSA levels and the IPSS before and after periodontal treatment is shown in Table 4. On average, subjects showed

\begin{tabular}{|l|c|c|}
\hline & N & Mean \pm SD or $\%$ \\
\hline Age (years) & & \\
\hline Race/Ethnicity & 17 & 63 \\
Caucasian & 9 & 33 \\
African American & 1 & 4 \\
Hispanic & & \\
\hline Prostate Inflammation & 21 & 81 \\
None/Mild & 5 & 19 \\
Moderate/Severe & 11 & 42 \\
\hline Prostate Malignant & 9 & 35 \\
None & 6 & 23 \\
Gleason score $\leq 7$ & 27 & $4.53 \pm 8.16$ \\
Gleason score $\geq 7$ & 27 & $10.63 \pm 7.46$ \\
\hline PSA levels (ng/mL) & 27 & $0.35 \pm 0.30$ \\
\hline IPSS & & \\
\hline IL-1 $\beta$ (pg/mL) & & \\
\hline
\end{tabular}

Table 1: Baseline characteristics of study population.

\begin{tabular}{|c|c|c|c|c|c|c|}
\hline & \multicolumn{2}{|c|}{ Prostate Inflammation } & \multicolumn{2}{|c|}{$\begin{array}{c}\text { Prostate } \\
\text { Malignancy }\end{array}$} & \multicolumn{2}{c|}{ Gleason Score } \\
\hline & $\begin{array}{c}\text { None/ } \\
\text { Mild } \\
(\mathrm{N}=21)\end{array}$ & $\begin{array}{c}\text { Moderate/ } \\
\text { Severe } \\
(\mathrm{N}=5)\end{array}$ & $\begin{array}{c}\mathrm{NO} \\
(\mathrm{N}=11)\end{array}$ & $\begin{array}{c}\text { YES } \\
(\mathrm{N}=15)\end{array}$ & $\begin{array}{c}\leq 7 \\
(\mathrm{~N}=9)\end{array}$ & $\begin{array}{c}>7 \\
(\mathrm{~N}=6)\end{array}$ \\
\hline Mean $\pm \mathrm{SD}$ & $4.3 \pm 9.1$ & $6.5 \pm 3.6$ & $3.2 \pm 1.4$ & $5.8 \pm 10.9$ & $4.1 \pm 4$ & $8.3 \pm 17$ \\
\hline $\mathrm{P}$ value & \multicolumn{2}{|c|}{$0.023^{*}$} & \multicolumn{2}{|c|}{0.65} & \multicolumn{2}{|c|}{0.61} \\
\hline *Statistically significant $(\mathrm{P}<0.05)$ & & \multicolumn{3}{|c|}{} \\
\hline
\end{tabular}

Table 2: PSA baseline values stratified by prostate inflammation, prostate malignancy and Gleason score. 


\begin{tabular}{|c|c|c|c|}
\hline & $\begin{array}{c}\text { Before } \\
\text { Treatment }\end{array}$ & $\begin{array}{c}\text { After } \\
\text { Treatment }\end{array}$ & Difference \\
\hline Clinical Attachment Level & $4.82 \pm 0.84$ & $3.16 \pm 0.51$ & $1.66 \pm 0.47^{*}$ \\
\hline Bleeding on Proving $(\%)$ & $64.14 \pm 15.31$ & $9.77 \pm 16.12$ & $56.9 \pm 23.84^{*}$ \\
\hline Gingival Index & $1.16 \pm 0.44$ & $0.38 \pm 0.40$ & $0.82 \pm 0.56^{*}$ \\
\hline Probing Depth $(\mathrm{mm})$ & $3.63 \pm 0.39$ & $2.75 \pm 0.26$ & $0.87 \pm 0.30^{*}$ \\
\hline Gingival Recession $(\mathrm{mm})$ & $1.19 \pm 0.56$ & $0.4 \pm 0.36$ & $0.79 \pm 0.29$ \\
\hline Plaque Index & $1.11 \pm 0.46$ & $0.26 \pm 0.31$ & $0.89 \pm 0.51^{*}$ \\
\hline${ }^{*}$ Statistically significant $(\mathrm{P}<0.05)$ & & \\
\hline
\end{tabular}

Table 3: Change in Mean and SD of clinical periodontal parameters 4-8 weeks after periodontal treatment.

decrease in PSA levels after periodontal treatment when compared to baseline $(0.34 \pm 1.14, \mathrm{p}=0.13) ; 21$ of 27 patients experienced a decrease in their PSA levels, and 6 had no change. When subjects were stratified by baseline PSA levels, subjects having higher PSA levels $(>4$ $\mathrm{ng} / \mathrm{ml}$ ) showed significant reduction in PSA levels, as compared to those having PSA levels $\leq 4 \mathrm{ng} / \mathrm{ml}(\mathrm{p}=0.008)$. IPSS also had statistical significant improvement 4-8 weeks after periodontal treatment $(1.6 \pm$ 3.2, $\mathrm{p}=0.02$ ) (Table 4).

Moderate correlation was observed between change PSA levels and changes in $\operatorname{CAL}(r=0.57, p=0.002)$; BOP $(r=0.42, p=0.031)$; and gingival recession $(\mathrm{r}=0.67, \mathrm{p}=0.001)$. Weak correlation was observed between a change PSA levels and changes in GI $(r=0.39, p=0.044)$ and IPSS ( $r=0.37, p=0.058$ ) (Table 5). The change in IPSS was not correlated with any clinical periodontal measures (data not shown).

\section{Discussion}

Periodontal treatment of patients with moderate/severe chronic periodontitis and prostatitis decreased serum PSA levels and the reduction is greater in men who have higher baseline PSA levels $(>4$ $\mathrm{ng} / \mathrm{ml}$ ) than those with low PSA levels $(\leq 4 \mathrm{ng} / \mathrm{ml})$. Serum IL- $1 \beta$ levels were low in all the participants and most men had undetectable levels of serum CRP. Thus, IL-1 $\beta$ and CRP were not included in further analysis. Patients reported prostatic symptoms also modestly decreased subjectively after periodontal treatment. Periodontal disease is a systemic condition that contributes to an inflammatory burden on the host through increased levels of pro-inflammatory cytokines [20-22]. Elevated levels of pro-inflammatory cytokines are also reported in men with prostatitis as compared to healthy individuals $[23,24]$. Joshi et al. showed that subjects having moderate/severe prostatitis and periodontitis have higher PSA levels than those with either condition alone. The authors suggested that periodontitis, through dissemination of pro-inflammatory cytokines, may exaggerate pre-existing inflammation of the prostate; disrupt the integrity of prostate glandular epithelium; and/or lead to inflammatory prostate enlargement, all of which in part explain increased serum PSA levels [12]. Non-surgical periodontal treatment has already been shown to decrease systemic inflammatory markers [25]. Thus, it is possible that decreased PSA levels after periodontal treatment might be attributed to reduction of these systemic pro-inflammatory cytokines, which in turn reduces the inflammatory burden on the prostate, leading to decreased local production of PSA. The reconstitution of the integrity of prostate glandular epithelium also makes it less leaky for PSA to enter the blood stream. Elimination of periodontal pathogens through periodontal therapy may reduce exposure of the prostate to invasion by bacteria and their toxins. Another hypothesis is that the periodontium may be a distant non-prostatic source of PSA, such as that reported in cases of breast cancer in females, where PSA level is reduced after oncologic treatment [26]. In the present study, significant improvement was also noticed in IPSS, 4 to 8 weeks after periodontal treatment. This self-reported observation by the participants may be a reflection of a reduction in the inflammatory process and a decrease in the size of the prostate gland.

In the present study, a positive relationship between PSA levels and the severity of prostate inflammation and malignancy also was noted. This observation is in agreement with MacLennan et al. [27] who reported a positive association between chronic intraprostatic inflammation and prostate cancer, supporting an etiologic link between inflammation and prostate carcinogenesis. Joshi et al. [12], suggested that an extraprostatic source of inflammation, such as the periodontium, may influence intraprostatic inflammation through dissemination of pro-inflammatory mediators. In this study, we showed that treating the periodontal disease reduced PSA levels and improved IPSS, which may be a reflection of reduction of intraprostatic inflammation. In light of these findings, treating periodontal disease might be a required approach to reduce prostate inflammation and possibly prostate cancer. Furthermore, given the uncertainty of PSA as screening tool for prostate biopsy, treating periodontal disease before recommending a biopsy may reduce unnecessary biopsies, especially in those patients with severe periodontitis and high PSA levels.

\section{Study Limitations}

Findings should be considered in terms of the study design, which did not permit a cause/effect relationship to be established between periodontitis and high PSA levels. In future large studies, a control group and the impact of confounders should be assessed. The other limitation of this study is that the PSA level determination was taken at one time point rather than over a longer period. This spot-check value of PSA is not necessarily reflective of true changes that may occur in PSA values. Multiple PSA values averaged over a longer period may provide more stable estimates of true change in PSA. In addition, estimates of prostatic volume and size were not considered in this study. Biopsy specimens represent only a small portion of the prostate gland and they may or may not be representative of the organ as a whole. Wellcontrolled longitudinal studies with larger sample size are warranted to further clarify the impact of periodontal treatment on prostate-specific antigen levels in patients with prostatitis and periodontitis.

\section{Conclusion}

Treatment of periodontal disease significantly improved clinical

\begin{tabular}{|c|c|c|c|c|}
\hline & $\begin{array}{c}\text { Before } \\
\text { Treatment }\end{array}$ & $\begin{array}{c}\text { After } \\
\text { Treatment }\end{array}$ & $\begin{array}{c}\text { Paired Mean } \\
\text { Difference }\end{array}$ & P Value \\
\hline PSA (N=27) & $4.53 \pm 8.16$ & $4.19 \pm 7.71$ & $0.34 \pm 1.14$ & \\
PSA $\leq 4 \mathrm{ng} / \mathrm{ml}(\mathrm{N}=17)$ & $1.5 \pm 1.4$ & $1.69 \pm 1.7$ & $-0.17 \pm 0.47$ & 0.13 \\
$\mathrm{PSA}>4 \mathrm{ng} / \mathrm{ml}(\mathrm{N}-10)$ & $9.7 \pm 11.9$ & $8.51 \pm 11.6$ & $1.19 \pm 1.44$ & \\
\hline IPSS & $10.63 \pm 7.46$ & $9.04 \pm 5.87$ & $1.59 \pm 3.24$ & $0.02 *$ \\
\hline *Statistically significant (P<0.05) & & & \\
\hline
\end{tabular}

Table 4: PSA and IPSS Mean values and SD before and after periodonta treatment.

\begin{tabular}{|c|c|c|}
\hline & Correlations with PSA & P value \\
\hline Clinical Attachment Level & 0.57 & $0.002^{*}$ \\
\hline Bleeding on Probing & 0.42 & $0.031^{*}$ \\
\hline Gingival Index & 0.39 & $0.044^{*}$ \\
\hline Gingival Recession & 0.67 & $0.001^{*}$ \\
\hline Probing Depth & 0.15 & 0.464 \\
\hline Plaque Index & 0.23 & 0.25 \\
\hline International Prostate Symptom Score & 0.37 & 0.058 \\
\hline *Statistically significant (P<0.05) & & \\
\hline
\end{tabular}

Table 5: Spearman correlation coefficients between the change in PSA levels and changes in periodontal parameters and IPSS. 
Citation: Alwithanani N, Bissada NF, Joshi N, Bodner D, Demko C, et al. (2015) Periodontal Treatment Improves Prostate Symptoms and Lowers Serum PSA in Men with High PSA and Chronic Periodontitis. Dentistry 5: 284. doi:10.4172/2161-1122.1000284

symptoms of prostatitis as well as reduced PSA levels in patients having high PSA levels $(>4 \mathrm{ng} / \mathrm{ml})$, in chronic prostatitis and periodontitis patients.

\section{Acknowledgements}

This study was sponsored by the Department of Periodontics and the Department of Urology, Case Western Reserve University.

\section{References}

1. König JE, Senge T, Allhoff EP, König W (2004) Analysis of the inflammatory network in benign prostate hyperplasia and prostate cancer. Prostate 58: 121 129.

2. Shah R, Mucci NR, Amin A, Macoska JA, Rubin MA (2001) Postatrophic hyperplasia of the prostate gland: neoplastic precursor or innocent bystander? Am J Pathol 158: 1767-1773.

3. De Marzo AM, Marchi VL, Epstein JI, Nelson WG (1999) Proliferative inflammatory atrophy of the prostate: implications for prostatic carcinogenesis. Am J Pathol 155: 1985-1992.

4. Gerstenbluth RE, Seftel AD, MacLennan GT, Rao RN, Corty EW, et al. (2002) Distribution of chronic prostatitis in radical prostatectomy specimens with upregulation of bcl-2 in areas of inflammation. J Urol 167: 2267-2270.

5. Wagenlehner FM, van Till JW, Magri V, Perletti G, Houbiers JG, et al. (2013) National Institutes of Health Chronic Prostatitis Symptom Index (NIH-CPSI) symptom evaluation in multinational cohorts of patients with chronic prostatitis/ chronic pelvic pain syndrome. Eur Urol 63: 953-959.

6. He W, Chen M, Zu X, Li Y, Ning K, et al. (2010) Chronic prostatitis presenting with dysfunctional voiding and effects of pelvic floor biofeedback treatment. BJU Int 105: 975-977.

7. Walz J, Perrotte P, Hutterer G, Suardi N, Jeldres C, et al. (2007) Impact of chronic prostatitis-like symptoms on the quality of life in a large group of men. BJU Int 100: 1307-1311.

8. Nadler RB, Collins MM, Propert KJ (2006) Chronic Prostatitis Collaborative Research Network. Prostate-specific antigen test in diagnostic evaluation ofchronic prostatitis/chronic pelvic pain syndrome. Urology 67:337-42.

9. Schatteman PH, Hoekx L, Wyndaele JJ, Jeuris W, Van Marck E (2000) Inflammation in prostate biopsies of men without prostatic malignancy or clinical prostatitis: correlation with total serum PSA and PSA density. Eur Urol 37: 404-412.

10. Nadler RB, Humphrey PA, Smith DS, Catalona WJ, Ratliff TL (1995) Effect of inflammation and benign prostatic hyperplasia on elevated serum prostate specific antigen levels. J Urol 154: 407-413.

11. Schaeffer AJ, Landis JR, Knauss JS (2002) Chronic Prostatitis CollaborativeResearch Network Group. Demographic and clinical characteristics of men withchronic prostatitis: the national institutes of health chronic prostatitis cohortstudy. J Urol 168:593-8.

12. Joshi N, Bissada NF, Bodner D, Maclennan GT, Narendran S, et al. (2010)
Association between periodontal disease and prostate-specific antigen levels in chronic prostatitis patients. J Periodontol 81: 864-869.

13. Townes CL, Ali A, Gross N, Pal D, Williamson S, et al. (2013) Prostate specific antigen enhances the innate defence of prostatic epithelium against Escherichia coli infection. Prostate 73: 1529-1537.

14. Krieger JN, Nyberg L Jr, Nickel JC (1999) NIH consensus definition and classification of prostatitis. JAMA 282: 236-7.

15. Offenbacher S (1996) Periodontal diseases: pathogenesis. Ann Periodontol 1: 821-878.

16. Jang TL, Schaeffer AJ (2003) The role of cytokines in prostatitis.World J Urol 21: 95-99.

17. Loe H, Silness J (1963) periodontal disease in pregnancy. I. Prevalence and severity. Acta Odontol Scand 21: 533-551.

18. Löe H (1967) The Gingival Index, the Plaque Index and the Retention Index Systems. J Periodontol 38: 610-616.

19. Barry MJ, Fowler FJ Jr, O'Leary MP, Bruskewitz RC, Holtgrewe HL, et al. (1992) The American Urological Association symptom index for benign prostatic hyperplasia. The Measurement Committee of the American Urological Association. J Urol 148: 1549-1557.

20. Ebersole JL, Machen RL, Steffen MJ, Willmann DE (1997) Systemic acutephase reactants, C-reactive protein and haptoglobin, in adult periodontitis. Clin Exp Immunol 107: 347-352.

21. Noack B, Genco RJ, Trevisan M, Grossi S, Zambon JJ, et al. (2001) Periodontal infections contribute to elevated systemic $\mathrm{C}$-reactive protein level. J Periodontol 72: $1221-1227$.

22. Loos BG, Craandijk J, Hoek FJ, Wertheim-van Dillen PM, van der Velden U (2000) Elevation of systemic markers related to cardiovascular diseases in the peripheral blood of periodontitis patients. J Periodontol 71: 1528-1534.

23. Korrovits P, Ausmees K, Mändar R, Punab M (2011) Seminal interleukin-6 and serum prostate-specific antigen as possible predictive biomarkers in asymptomatic inflammatory prostatitis. Urology 78: 442-446.

24. Nadler RB, Koch AE, Calhoun EA, Campbell PL, Pruden DL, et al. (2000) IL1 beta and TNF-alpha in prostatic secretions are indicators in the evaluation of men with chronic prostatitis. J Urol 164: 214-218.

25. D'Aiuto F, Nibali L, Parkar M, Suvan J, Tonetti MS (2005) Short-term effects of intensive periodontal therapy on serum inflammatory markers and cholesterol. J Dent Res 84: 269-273.

26. Mashkoor FC, Al-Asadi JN, Al-Naama LM (2013) Serum level of prostatespecific antigen (PSA) in women with breast cancer. Cancer Epidemiol 37: 613-618.

27. MacLennan GT, Eisenberg R, Fleshman RL, Taylor JM, Fu P, et al. (2006) The influence of chronic inflammation in prostatic carcinogenesis: a 5-year followup study. J Urol 176: 1012-1016. 